\title{
Improvement of clinical quality indicators through reorganization of the acute care by establishing an emergency department-a register study based on data from national indicators
}

\author{
Maria Søe Mattsson ${ }^{1,2^{*}}$, Nick Mattsson ${ }^{2,3}$ and Hanne B Jørsboe ${ }^{2}$
}

\begin{abstract}
Background: The Emergency Departments (EDs) reorganization process in Denmark began in 2007 and includes creating a single entrance for all emergency patients, establishing triage, having a specialist in the front and introducing the use of electronic overview boards and electronic patient files. The aim of this study was to investigate the quality of acute care in a re-organized ED based on national indicator project data in a pre and post reorganizational setting.

Methods: Quasi experimental design was used to examine the effect of the health care quality in relation to the reorganization of an ED. Patients admitted at Nykøbing Falster Hospital in 2008 or 2012 were included in the study and data reports from the national databases (RKKP) regarding stroke, COPD, heart failure, bleeding and perforated ulcer or hip fracture were analysed. Holbæk Hospital works as a control hospital.

Chi-square test was used for analysing significant differences from pre-and post intervention and Z-test to compare the experimental groups to the control group $(\mathrm{HOL}) . P<0.05$ was considered statistically significant.

Results: We assessed 4584 patient cases from RKKP. A significant positive change was seen in all of the additional eight indicators related to stroke at NFS ( $<<0.001)$; however, COPD indicators were unchanged in both hospitals. In NFS two of eight heart failure indicators were significantly improved after the reorganization $(p<0.01)$. In patients admitted with a bleeding ulcer 2 of 5 indicators were significantly improved after the reorganization in NFS and $\mathrm{HOL}(\mathrm{p}<0.01)$. Both compared hospitals showed significant improvements in the two indicators concerning hip fracture $(p<0.001)$. Significant reductions in the 30 day-mortality in patients admitted with stroke were seen when the pre- and the post-intervention data were compared for both NFS and HOL $(p=0.024)$.

Conclusions: During the organisation of the new EDs, several of the indicators improved and the overall 30 days mortality decreased in the five diseases. The development of a common set of indicators for monitoring acute treatment at EDs in Denmark is recommended.
\end{abstract}

Keywords: Emergency Department, Reorganization, Indicators, Mortality

\footnotetext{
* Correspondence: mariasoee@gmail.com

'Faculty of Health Science, University of Southern Denmark, 5230 Odense M,

Denmark

${ }^{2}$ Emergency Department, Hospital of Nykøbing Falster, 4800 Nykøbing

Falster, Denmark

Full list of author information is available at the end of the article
}

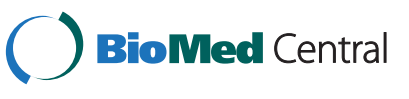

(c) 2014 Mattsson et al.; licensee BioMed Central Ltd. This is an Open Access article distributed under the terms of the Creative Commons Attribution License (http://creativecommons.org/licenses/by/4.0), which permits unrestricted use, distribution, and reproduction in any medium, provided the original work is properly credited. The Creative Commons Public Domain Dedication waiver (http://creativecommons.org/publicdomain/zero/1.0/) applies to the data made available in this article, unless otherwise stated. 


\section{Background}

In Denmark the choice was made to reorganise the acute care by the establishment of Emergency Departments with observation units. The aim of the new EDs was to improve the quality of the diagnostic process and allow for an earlier diagnosis and treatment of all types of acute patients based on international experience [1]. Emergency Medicine (EM) as a discipline has existed for more than 40 years in the USA and has served as a model for international experience in this field as well as the interventions in this study [2].

The international experiences have shown that the quality of treatment in EDs can be improved by using triage [3-6], optimising the flow of patients into and out of the ED [3,7-9], optimising teamwork [4] and by the introduction of a fast-track diagnostic workup for patients with less severe symptoms [9].

A strong tradition of monitoring the health care services and quality of health care exits in Denmark; however, there are currently no general accepted national quality indicators for the acute treatment of patients [10]. Although a few clinical databases related to Emergency Medicine were under development in 2013 [11,12] the usual quality measurements of choice have been to monitor different time intervals, e.g. door to treatment, which are easy accessible data for administrative use. These intervals, however, does not differentiate properly between the different acute care needs of patients.

The aim of this study is to investigate the impact of reorganization of the acute care in a new Emergency Department with observation units on the quality of health care, including mortality rate, as monitored by five selective acute conditions; stroke, acute gastrointestinal bleeding and perforation, heart failure, COPD, COPD with pneumonia and hip fractures.

\section{Methods}

\section{Study design and setting}

A quasi experimental design was used, including both pre- (baseline) and post-intervention data. The uniform package of interventions constituted several elements, including the following: an enhanced focus on improved admission, early stabilisation and treatment of patients through the implementation of a triage system, earlier bedside assessment of patients by nurses, an increased availability of senior doctors, improved competence of the entire staff and the implementation of electronic white boards and patient files to increase the focus on patient safety. Furthermore, a specific protocol for stroke patients served as a tool for optimising the treatment of patients and was used in the Hospital of Nykøbing Falster (NFS) as an applicable model for the treatment of acute diseases in general. The organizational changes are described in Figure 1.
Baseline data (pre-intervention) were collected from the NIP data register in the period January 2008 - December 2008 and included patients who were admitted to the ED at NFS. Post-intervention data were collected from the Region's Clinical Quality Development Programme (RKKP) [10] from January 2012 - December 2012 and comprised patients who were admitted to the ED at the same hospital. The control group consisted of comparable patients (as defined in the national inclusion criteria) from another community hospital in Region Zealand, the ED at the Hospital of Holbæk (HOL). By using HOL as a control hospital, it provides us with the opportunity to compare the changes in the indicators, as $\mathrm{HOL}$ underwent the same reorganization process in the ED although organizational differences existed between the two hospitals.

NFS has an uptake area with 140.000 citizens. The activity level within the ED changed from 2008 to 2012. A reduction of 3.476 patients with small injuries was observed during this time period (24.249 in 2008; 20.773 in 2012), whereas the total number of patients admitted to the ED increased by 3.427 (12.861 in 2008; 16.288 in 2012) (OPUS: local administrative system). The choice was made not to compare each year between 2008 and 2012 as the implementation of interventions were initiated in 2009 and first completed in the year of 2011. Additionally the interventions were adjusted during the implementation process.

\section{Population and measurements}

To measure the quality of healthcare, designated by a national board of specialists within each disease area selected a series of measures (indicators). The indicators have been selected as they are considered particularly important in the assessment of whether the quality of care is at the desired level [10]. Specific indicators for each disease were selected based on evidence of their relevance for the acute admission of patients and their potential benefits early in the patients' pathway through the acute care process. The indicators measures either entire processes or specific outcomes. The processes represent data of examinations, treatment by physicians, treatment by other health professionals, screenings and outcome indicators represent data regarding readmissions and mortality. The RKKP (former NIP database) has expanded its scope through the years, limiting the indicators to those present in both 2008 and 2012. Because of the very few hospitalized patients with heart failure at HOL, the management of department decided to stop reporting to RKKP in 2011 and resulting in missing data in the results.

The study population consisted of acutely ill patients who sought medical attention in the ED and who met the criteria as reported to the Region's Clinical Quality 


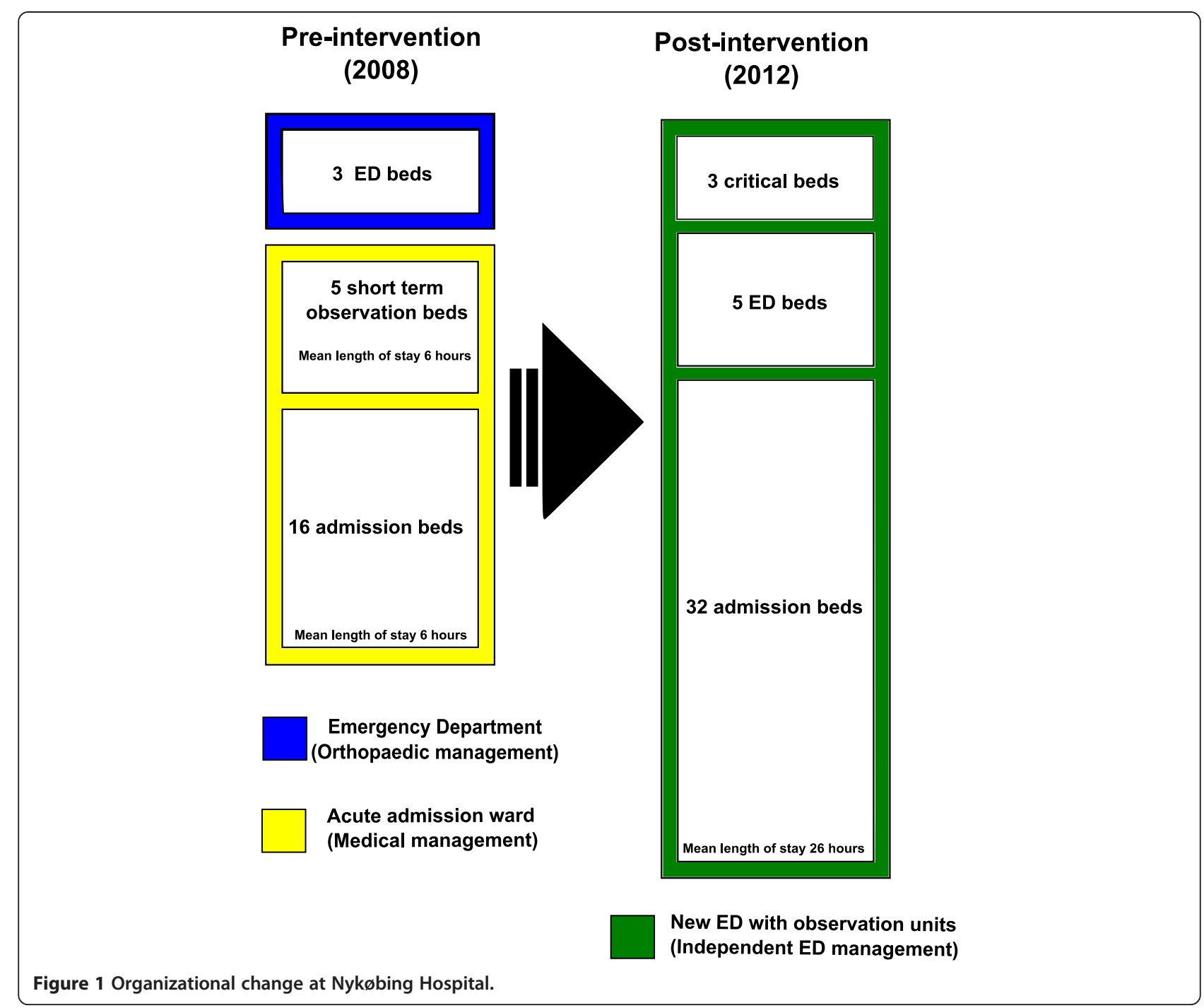

Development databases for the following diagnoses: stroke, COPD, heart failure, hip fracture and acute gastrointestinal bleeding and perforation [13-17]. All are among the 20 most common illnesses seen in an emergency care setting.

We used these data as a benchmark for critical indicators and as a quality standard in the reorganization of the EDs with pre and post analyses. As the indicators are a national requirement, data sets could be measured against comparable hospitals as well as data on a national level.

This study utilizes indicators used in all Danish hospitals over the last seven years and are all validated by the RKKP based on a clinical assessment of three main issues; does the indicator measure the clinical pathway of interest; is the indicator able to identify known variations in the quality of different health care departments considering the patient population as well and are golden standards available [10].

\section{Data analysis}

Frequency distributions were constructed for the datasets and interpreted using frequencies and percentages. To test for significant differences, the results were analysed using the chi-squared test. A twoproportion z-test was used to compare the experimental groups to the control group (HOL). Categories with fewer than 5 responses were folded with an adjacent category. In all analyses $\mathrm{p}<0.05$ was considered statistically significant. Data were analyzed using STATA version 11 software.

\section{Ethical considerations}

Upon application to RKKP we got access to the relevant databases and permission to use data in the study. Patient anonymity was protected throughout the research process. This study was approved by the hospitals of NFS and HOL as well as the Hospitals Ethics Committee and the Helsinki Declaration was complied with. The 
study was approved by the Danish Data Protection Agency.

\section{Results}

We assessed 4584 patient cases from RKKP. In 2008 (pre-intervention) 1914 patient cases were included and in 2012 (post-intervention) 2670 patient cases. The mean age and gender of the participants in the pre- and post-intervention groups did not differ significantly in NFS. Fewer women with hip fractures were admitted in 2012 in HOL. Between hospitals, significant gender differences is seen for COPD in 2012 and hip-fracture both pre- and post intervention (Table 1). Changes of indicators of each of the six diagnoses from pre- to post intervention are described in the following.

\section{Stroke}

A significant positive change in all of the additional eight indicators related to stroke at NFS was seen in patients admitted with a tentative diagnosis of stroke, Table 2. At HOL 5 of 8 stroke indicators showed a positive significant change while one indicator decreased significantly; "Assessed by a physiotherapist" (pre: $94.53 \%$ vs. post: 89.73\%, $\mathrm{p}=0.002)$ (Table 2).

Despite the general improvement three indicators at NFS were in post intervention data analyses still below national standard; Assessment of need for occupational therapy, nutrition screening and ultrasound/CT-/MR angiography of the neck vessels, Table 2 .

\section{COPD}

COPD indicators were unchanged comparing the pre- and post-intervention data from NFS and HOL. Although not significant, there was a decreased tendency of readmission of patients with COPD treated at NFS $(25.00 \%$ vs. $18.60 \%$, $\mathrm{p}=0.21$ ) making the post intervention data similar to HOL, which showed increasing readmission tendencies in the same period $(14.29 \%$ vs. $18.49 \%, \mathrm{p}=0.29)$ (Table 3$)$.

\section{Heart failure}

In NFS two of eight heart failure indicators were significantly improved after the reorganization: "echocardiography" $(88.97 \%$ vs. $97.55 \%, p=0.001)$ and "exercise by physiotherapist" $(11.32 \%$ vs. $41.42 \%, \mathrm{p}<0.0001)$ while data demonstrate a significant decrease in to 2 out of 8 indicators; "NYHA classification" (96.32\% vs. $90.69 \%, \mathrm{p}=0.05)$ and "initiated a structured training program" (92.59\% vs. $84.62 \%, \mathrm{p}=0.05)$. Comparison to $\mathrm{HOL}$ is not possible because of missing data from $\mathrm{HOL}$ in 2012 (Table 4).

\section{Bleeding and perforated ulcer}

In patients admitted with a bleeding ulcer 2 of 5 indicators were significantly improved after the reorganization in NFS; "endoscopy within 24 hours" (60.00\% vs. $84.16 \%, p=0.005)$ and "endoscopy treatment of rebleeding" ( $40.00 \%$ vs. $100.00 \%, \mathrm{p}=0.018$ ). In HOL, 2 of 5 indicators also improved significantly (both: $\mathrm{p}<$ 0.05) (Table 5).

No significant improvements were seen in patients admitted with a perforated ulcer in NFS, consistent with results from HOL, although the indicator measuring "daily weight control" improved in HOL (33.33\% vs. $100.00 \%, p=0.007)$. Generally the numbers of patients in this section are low (Table 6).

Table 1 Study population: Nykøbing and Holbæk Hospitals

\begin{tabular}{|c|c|c|c|c|c|c|c|c|}
\hline \multirow[b]{2}{*}{ Diagnoses } & \multirow[b]{2}{*}{ Location } & \multicolumn{3}{|l|}{2008} & \multicolumn{3}{|l|}{2012} & \multirow[b]{2}{*}{$\begin{array}{l}\text { P-value Proportions z-test } \\
\text { between years at hospital level }\end{array}$} \\
\hline & & $\begin{array}{l}\text { Patients } \\
\text { reported } \\
2008(n)\end{array}$ & $\begin{array}{l}\text { Mean age } \\
\text { (range) }\end{array}$ & $\begin{array}{l}\text { Gender } \\
\text { (female) } \\
\text { Percent }\end{array}$ & $\begin{array}{l}\text { Patients } \\
\text { reported } \\
2012(n)\end{array}$ & $\begin{array}{l}\text { Mean age } \\
\text { (range) }\end{array}$ & $\begin{array}{l}\text { Gender } \\
\text { (female) } \\
\text { Percent }\end{array}$ & \\
\hline \multirow[t]{2}{*}{ Stroke } & NFS & 293 & 72.46 (42-99) & 43 & 212 & 72.63 (34-97) & 48 & 0.133 \\
\hline & $\overline{\mathrm{HOL}}$ & 652 & $70.76(33-102)$ & 47 & 634 & 71.21 (34-99) & 48 & 0.356 \\
\hline \multirow[t]{2}{*}{ COPD } & NFS & 69 & 71.28 (38-93) & 45 & 530 & 70.60 (34-94) & $45^{*}$ & 0.490 \\
\hline & $\overline{\mathrm{HOL}}$ & 121 & 70.75 (49-89) & 54 & 437 & 70.64 (30-98) & $57^{*}$ & 0.247 \\
\hline \multirow[t]{2}{*}{ Heart failure } & NFS & 136 & 69.90 (36-98) & 31 & 205 & 70.82 (22-94) & 22 & 0.026 \\
\hline & $\mathrm{HOL}$ & 109 & $66.30(19.93)$ & 32 & $\#$ & & & \\
\hline \multirow[t]{2}{*}{ Bleeding ulcer } & NFS & 29 & 71.29 (37-92) & 52 & 104 & 72.14 (36-94) & 44 & 0.237 \\
\hline & $\overline{\mathrm{HOL}}$ & 10 & $78.17(49-88)$ & 70 & 64 & 73.79 (45-94) & 44 & 0.061 \\
\hline \multirow[t]{2}{*}{ Perforated ulcer } & NFS & 6 & $65.80(48-81)$ & 67 & 16 & 72.50 (44-94) & 25 & 0.035 \\
\hline & $\overline{\mathrm{HOL}}$ & 4 & $61.53(49-76)$ & 75 & 8 & 65.23 (29-89) & 50 & 0.203 \\
\hline \multirow[t]{2}{*}{ Hip fracture } & NFS & 214 & $81.47(66-101)$ & $67^{*}$ & 248 & $82.14(65-100)$ & $73^{*}$ & 0.108 \\
\hline & $\overline{\mathrm{HOL}}$ & 271 & $84.29(65-102)$ & $75^{*}$ & 212 & $81.73(65-98)$ & $65^{*}$ & 0.009 \\
\hline
\end{tabular}

*: z-test $\mathrm{p}<0.05$ Gender differences between NFS and control hospital (HOL).

\#Data from HOL 2012 are missing. 
Table 2 Stroke indicators

\begin{tabular}{|c|c|c|c|c|}
\hline Indicator & Location & $\begin{array}{l}\text { Pre percent } \\
\text { (n) } 2008\end{array}$ & $\begin{array}{l}\text { Post percent } \\
\text { (n) } 2012\end{array}$ & $\begin{array}{l}\text { p-value } \\
\text { chi2-test }\end{array}$ \\
\hline \multirow{4}{*}{$\begin{array}{l}\text { Patients admitted directly/transferred within second day } \\
\text { of hospitalization to a stroke unit? }\end{array}$} & NFS & $65.86(161 / 249)^{*}$ & $97.64(207 / 212)^{*}$ & $<0.0001$ \\
\hline & $\mathrm{HOL}$ & $99.85(649 / 650)^{*}$ & $99.21(627 / 632)^{*}$ & 0.095 \\
\hline & National (mean) & 89.00 & 94.00 & \\
\hline & Standard \% & $\min .90$ & $\min .90$ & \\
\hline \multirow{4}{*}{$\begin{array}{l}\text { Patients receiving antiplatelet therapy within second } \\
\text { hospitalization days? }\end{array}$} & NFS & $75.95(120 / 158)^{*}$ & $96.89(156 / 161)$ & $<0.0001$ \\
\hline & $\mathrm{HOL}$ & $92.20(402 / 436)^{*}$ & $97.01(455 / 469)$ & 0.001 \\
\hline & National (mean) & 87.00 & 94.00 & \\
\hline & Standard \% & $\min .95$ & $\min .95$ & \\
\hline \multirow[t]{4}{*}{ Patients receiving oral anticoagulation therapy within 14 days? } & NFS & $60.00(12 / 20)^{*}$ & $100(20 / 20)$ & 0.002 \\
\hline & $\mathrm{HOL}$ & $83.61(51 / 61)^{*}$ & $96.25(77 / 80)$ & 0.010 \\
\hline & National (mean) & 73.00 & 89.00 & \\
\hline & Standard \% & $\min .95$ & $\min .95$ & \\
\hline \multirow[t]{4}{*}{ Patients with CT/MR scans on the day of admission? } & NFS & $44.85(122 / 272)^{*}$ & $81.99(173 / 211)$ & $<0.0001$ \\
\hline & $\mathrm{HOL}$ & $86.97(554 / 637)^{*}$ & $84.54(536 / 634)$ & 0.216 \\
\hline & National (mean) & 67.00 & 86.00 & \\
\hline & Standard \% & $\min .80$ & $\min .80$ & \\
\hline \multirow{4}{*}{$\begin{array}{l}\text { Patients assessed by a physiotherapist within second } \\
\text { hospitalization day? }\end{array}$} & NFS & $68.80(172 / 250)^{*}$ & $93.00(186 / 200)$ & $<0.0001$ \\
\hline & $\mathrm{HOL}$ & $94.53(588 / 622)^{*}$ & $89.73(524 / 584)$ & 0.002 \\
\hline & National (mean) & 73.00 & 88.00 & \\
\hline & Standard \% & $\min .90$ & $\min .90$ & \\
\hline \multirow{4}{*}{$\begin{array}{l}\text { Patients assessed by an occupational therapist within } \\
\text { second hospitalization day? }\end{array}$} & NFS & $60.64(151 / 249)^{*}$ & $82.84(169 / 204)$ & $<0.0001$ \\
\hline & $\mathrm{HOL}$ & $81.28(508 / 625)^{*}$ & $81.60(479 / 587)$ & 0.886 \\
\hline & National (mean) & 70.00 & 86.00 & \\
\hline & Standard \% & $\min .90$ & $\min .90$ & \\
\hline \multirow[t]{4}{*}{ Patients' nutrition status screened within second hospitalization day? } & NFS & $34.00(68 / 200)^{*}$ & $48.94(92 / 188)^{*}$ & 0.003 \\
\hline & $\mathrm{HOL}$ & $92.36(592 / 641)^{*}$ & $97.12(607 / 625)^{*}$ & $<0.0001$ \\
\hline & National (mean) & 68.00 & 84.00 & \\
\hline & Standard \% & $\min .90$ & $\min .90$ & \\
\hline \multirow{4}{*}{$\begin{array}{l}\text { Ultrasound/CT/MR angiography of the neck vessels } \\
\text { within } 14 \text { days? }\end{array}$} & NFS & $20.65(32 / 155)$ & $80.42(115 / 143)^{*}$ & $<0.0001$ \\
\hline & $\mathrm{HOL}$ & $10.34(42 / 406)$ & $69.13(309 / 447)^{*}$ & $<0.0001$ \\
\hline & National (mean) & 42.00 & 84.00 & \\
\hline & Standard \% & $\min .90$ & $\min .90$ & \\
\hline
\end{tabular}

NFS and HOL compared to the national mean and the national standard: 2008 and 2012.

*Significant differences between hospitals compared in years (two proportions z-test).

\section{Hip fracture}

Both comparing hospitals showed significant improvements in the two indicators concerning hip fracture, comparing pre- and post-intervention measures (all: $\mathrm{p}<0.006)$; except for the decreasing rehabilitation indicator in NFS in the same period $(95.75 \%$ vs. $82.27 \%, \mathrm{p}<0.0001$ ) (Table 7).

\section{Mortality}

Significant reductions in the 30 day-mortality in patients admitted with stroke were seen when the pre- and the post-intervention data were compared for both NFS
(12.29\% vs. $5.66 \%, \mathrm{p}=0.012)$ and HOL $(11.81 \%$ vs. $8.04 \%$, $\mathrm{p}=0.024)$. A significant reduction in 1 year mortality was also observed at NFS in patients with heart failure (44.71\% vs. $15.10 \%, \mathrm{p}<0.0001)$. Despite small numbers of patients in that section, mortality due to bleeding ulcers was significant lower in NFS before the reorganization than after compared to HOL that showed significantly decreased mortality in the same period (Table 8).

After the establishment of the new ED in NFS 63\% of indicators meet national standard compared to $30 \%$ before and in $\mathrm{HOL} 55 \%$ of the indicators meet national standards compared to $60 \%$ before. 
Table 3 COPD indicators

\begin{tabular}{|c|c|c|c|c|}
\hline Indicator & Location & $\begin{array}{l}\text { Pre percent } \\
\text { (n) } 2008\end{array}$ & $\begin{array}{l}\text { Post percent } \\
\text { (n) } 2012\end{array}$ & $\begin{array}{l}\mathrm{p} \text {-value } \\
\text { chi2-test }\end{array}$ \\
\hline \multirow[t]{4}{*}{ Hospitalised for acute exacerbation and receipt of NIV** treatment } & NFS & $4.35(3 / 69)$ & $6.60(35 / 530)$ & 0.470 \\
\hline & $\mathrm{HOL}$ & $4.13(5 / 119)$ & $9.15(40411)$ & 0.073 \\
\hline & National (mean) & 8.00 & 9.00 & \\
\hline & Standard \% & $\min .10$ & $\min .10$ & \\
\hline \multirow[t]{4}{*}{ Hospitalised for acute exacerbation and readmission within 30 days } & NFS & $25.00(17 / 68)^{*}$ & $18.60(93 / 500)$ & 0.210 \\
\hline & $\mathrm{HOL}$ & $14.29(17 / 119)^{*}$ & $18.49(76 / 411)$ & 0.288 \\
\hline & National (mean) & \# & 18.00 & \\
\hline & Standard \% & None & None & \\
\hline
\end{tabular}

NFS and HOL compared to the national mean and the national standard: 2008 and 2012.

*Significant differences between hospitals compared in years (two proportions z-test).

**NIV:" non-invasive ventilation".

\#Data stems from re-auditation.

\section{Discussion}

This study aimed to investigate whether reorganization of EDs, with observation units and several interventions improve clinical quality of five specific diseases, evaluated with measures defined by Danish health care authorities [1]. The results indicate an overall improved clinical quality and a reduced mortality of patients with stroke, heart failure, bleeding ulcer and hip fracture after the establishment of the ED with observation units compared to baseline.

Overall, data shows a significant positive change in 53\% of all the indicators in patients admitted in NFS and $46 \%$ of all the indicators in HOL. We argue that it could reflect patient safety issues and flow indicators in five common diseases seen in the ED. Internationally, other studies have demonstrated that the reorganization, in relation to the establishment of EDs, optimize patient safety as well as the flow of patients into and out of the ED $[2,6,7,18,19]$. Mortality decreased significantly in patients admitted with stroke in both hospitals and in patients admitted with heart failure in NFS. The mortality data are credible because they are crosschecked with mortality data from The Danish National Patient Registry (LPR). Other interventional studies show similar results on various types of indicators, e.g. mortality, readmissions and waiting time. Generally a consensus of indicators seems to be missing in literature. Our results supports international literature indicating that these improvements might originate from the implementation of the new concept for diagnosing and treating acute patients $[3,9,20]$.

Several studies have shown that EDs with observation units and senior physicians in front might improve decision-making and workflow and demonstrates a more efficient use of hospital space. Patients are discharged earlier using fewer bed days and with readmission rates less than or equal to the first-time admission rates [10,21-23], indicating that the earlier discharge is not selling out on patient condition. Our results indicate a general decreased mortality in five of the disease groups in NFS; however, it includes a COPD group with unchanged or higher mortality in post data analyses, even though readmission rates shows consistent decrease in the same period. This could possibly be explained in the structure of the patient intake in the NFS ED. In the pre reorganization setup, very ill COPD patients with acute respiratory failure were directly admitted to the intensive care unit or directly in the COPD department and therefore not accounted for in the analyses. In the post reorganization setup, all patients, including the ones with respiratory failure, are seen in the ED, resulting in increasing mortality.

The nationally defined protocol for handling of patients with stroke has been used in the ED in NFS with a specific aim to implement standardized routines and increase competencies among staff in other care areas [24]. The use of the stroke protocol is seen in most other hospitals in Region Zealand. NFS faced a special challenge in 2009 since the results were significantly below the national standard as measured by the indicators for hip fracture. The results improved with the reorganization and they are similar in HOL as well as other hospitals nationwide [10]. The improvements, however, should not be attributed to the reorganization alone, as the general treatment has changed nationally over years including improved treatment protocols in some diseases and easier access to advanced treatment, e.g. fibrinolysis in stroke patients.

The two compared hospitals had important differences in their organization of the EDs. HOL already had its own group of senior and junior physicians in February 2009, whereas NFS was highly dependent on doctors from other departments to work in the ED; however, the observational beds were already established in 2009 in NFS compared to 2011 in HOL. Thus, the two hospitals faced different challenges in the reorganization period, emphasising the choice of the final comparison year as 2012. 
Table 4 Heart failure indicators

\begin{tabular}{|c|c|c|c|c|}
\hline Indicator & Location & $\begin{array}{l}\text { Pre percent } \\
\text { (n) } 2008\end{array}$ & $\begin{array}{l}\text { Post percent } \\
\text { (n) } 2012\end{array}$ & $\begin{array}{l}\text { p-value } \\
\text { chi2-test }\end{array}$ \\
\hline \multirow[t]{4}{*}{ Echocardiography } & NFS & $88.97(121 / 136)$ & $21.57(44 / 204)$ & 0.001 \\
\hline & $\mathrm{HOL}$ & $100(109 / 109)$ & $\#$ & \\
\hline & National (mean) & 87.00 & 94.00 & \\
\hline & Standard \% & $\min .90$ & $\min .90$ & \\
\hline \multirow[t]{4}{*}{ NYHA classification } & NFS & $96.32(131 / 136)^{*}$ & $90.69(185 / 204)$ & 0.047 \\
\hline & $\mathrm{HOL}$ & $100(109 / 109)^{*}$ & $\#$ & \\
\hline & National (mean) & 74.00 & 92.00 & \\
\hline & Standard \% & $\min .90$ & $\min .90$ & \\
\hline \multirow{4}{*}{$\begin{array}{l}\text { Started or attempted treatment with ACE inhibitor/ATIl-receptor antagonist? } \\
\text { (only patients with impaired systolic function) }\end{array}$} & NFS & $90.99(101 / 111)^{*}$ & $89.94(152 / 169)$ & 0.771 \\
\hline & $\mathrm{HOL}$ & $100(89 / 89)^{*}$ & $\#$ & \\
\hline & National (mean) & 83.00 & 92.00 & \\
\hline & Standard \% & $\min .90$ & $\min .90$ & \\
\hline \multirow{4}{*}{$\begin{array}{l}\text { Started or attempted treatment with beta blockers (only patients with } \\
\text { impaired systolic function) }\end{array}$} & NFS & $88.18(97 / 110)$ & $84.02(142 / 169)$ & 0.333 \\
\hline & $\mathrm{HOL}$ & $90.91(80 / 88)$ & $\#$ & \\
\hline & National (mean) & 72.00 & 88.00 & \\
\hline & Standard \% & $\min .80$ & $\min .80$ & \\
\hline \multirow{4}{*}{$\begin{array}{l}\text { Started or attempted treatment with aldosterone antagonist (only patients } \\
\text { with impaired systolic function) }\end{array}$} & NFS & $39.78(37 / 93)^{*}$ & $48.44(62 / 128)$ & 0.202 \\
\hline & $\overline{\mathrm{HOL}}$ & $20.00(14 / 70)^{*}$ & $\#$ & \\
\hline & National (mean) & 25.00 & 36.00 & \\
\hline & Standard \% & $\min .35$ & $\min .35$ & \\
\hline \multirow[t]{4}{*}{ Referred to physical exercise by physiotherapist } & NFS & $11.32(12 / 106)$ & $41.42(70 / 169)$ & $<0.0001$ \\
\hline & $\mathrm{HOL}$ & $10.23(9 / 88)$ & $\#$ & \\
\hline & National (mean) & 19.00 & 28.00 & \\
\hline & Standard \% & $\min .30 \%$ & $\min .30 \%$ & \\
\hline \multirow[t]{4}{*}{ Initiated a structured training program } & NFS & $92.59(100 / 108)^{*}$ & $84.62(143 / 169)$ & 0.048 \\
\hline & $\mathrm{HOL}$ & $100(89 / 89)^{*}$ & $\#$ & \\
\hline & National (mean) & 73.00 & 84.00 & \\
\hline & Standard \% & $\min .80$ & $\min .80$ & \\
\hline \multirow[t]{4}{*}{ Readmitted within 4 weeks } & NFS & $4.51(6 / 133)^{*}$ & $7.07(14 / 198)$ & 0.338 \\
\hline & $\mathrm{HOL}$ & $10.19(11 / 108)^{*}$ & $\#$ & \\
\hline & National (mean) & 8.00 & 9.00 & \\
\hline & Standard \% & $\max .10$ & $\max .10$ & \\
\hline
\end{tabular}

NFS and HOL compared to the national mean and the national standard: 2008 and 2012.

* Significant differences between hospitals compared in years (two proportions z-test).

\#Data missing. HOL stopped reporting to the database in 2011.

To our knowledge this is the first study to investigate the quality of acute care in a representative group of acute conditions before and after in a reorganized ED over a longer period of time. Earlier studies in Denmark have focused on groups of specific diagnoses [25]. These studies are, however, done without consistency throughout studies and in various ways [26]. In the absence of a standard definition of quality, measuring clinical quality in an ED is complex and difficult and fosters the question of which indicators are the most representative of a specific clinical setting [26,27].

It might be argued that using these indicators as a surrogate marker of clinical quality is inadequate; however, the indicators are the measuring tool of national choice, making it necessary to relate to. As great differences in accessibilities to different paraclinical tests as well as various medical specialists exists between hospitals, it is important to compare similar hospitals. Great concerns have been raised from the peripheral hospitals that the national indicators reflect standard care in a university hospital setting, but not in a peripheral hospital. This emphasise the importance of the positive post reorganizational results achieved in NFS as a peripheral hospital.

Whether the improvements observed were due to the establishment of the ED or as a result of a general improved 
Table 5 Bleeding ulcer indicators

\begin{tabular}{|c|c|c|c|c|}
\hline Indicator & Location & $\begin{array}{l}\text { Pre percent } \\
\text { (n) } 2008\end{array}$ & $\begin{array}{l}\text { Post percent } \\
\text { (n) } 2012\end{array}$ & $\begin{array}{l}\text { p-value } \\
\text { chi2-test }\end{array}$ \\
\hline \multirow[t]{4}{*}{ Endoscopy within 24 hours from admission/time to decision about treatment } & NFS & $60.00(18 / 30)^{*}$ & $84.16(85 / 101)^{*}$ & 0.005 \\
\hline & $\overline{\mathrm{HOL}}$ & $90.00(9 / 10)^{*}$ & $71.67(43 / 60)^{*}$ & 0.219 \\
\hline & National (mean) & 83.00 & 84.00 & \\
\hline & Standard \% & $\min .85$ & $\min .85$ & \\
\hline \multirow[t]{4}{*}{ Treatment/therapeutic endoscopy, } & NFS & $66.67(6 / 9)$ & $90.70(39 / 43)$ & 0.055 \\
\hline & $\mathrm{HOL}$ & $100(6 / 9)$ & $88.24(15 / 17)$ & 0.379 \\
\hline & National (mean) & 92.00 & 94.00 & \\
\hline & Standard \% & $\min .90$ & $\min .90$ & \\
\hline \multirow[t]{4}{*}{ Rebleeding after primary treatment } & NFS & $16.67(1 / 6)^{*}$ & $10.42(5 / 48)$ & 0.646 \\
\hline & $\mathrm{HOL}$ & $66.67(4 / 6)$ & $9.52(2 / 21)$ & 0.003 \\
\hline & National (mean) & 16.00 & 12.00 & \\
\hline & Standard \% & $\max .15$ & $\max .15$ & \\
\hline \multirow[t]{4}{*}{ Endoscopic treatment of rebleeding } & NFS & $40.00(2 / 5)$ & $100(7 / 7)^{*}$ & 0.018 \\
\hline & $\mathrm{HOL}$ & $40.00(2 / 5)$ & $55.56(5 / 9)^{*}$ & 0.577 \\
\hline & National (mean) & 72.00 & 73.00 & \\
\hline & Standard \% & $\min .75$ & $\min .75$ & \\
\hline \multirow[t]{4}{*}{ Surgical treatment of primary bleeding or rebleeding } & NFS & $10.00(3 / 30)$ & $4.81(10 / 104)$ & 0.290 \\
\hline & $\mathrm{HOL}$ & $30.00(3 / 10)$ & $4.76(3 / 63)$ & 0.007 \\
\hline & National (mean) & 5.00 & 4.00 & \\
\hline & Standard \% & $\max .10$ & $\max .10$ & \\
\hline
\end{tabular}

NFS and HOL compared to the national mean and the national standard: 2008 and 2012.

*Significant differences between hospitals compared in years (two proportions z-test).

Table 6 Perforated ulcer indicators

\begin{tabular}{|c|c|c|c|c|}
\hline Indicator & Location & Pre percent (n) & Post percent (n) & $\mathrm{p}$-value chi2-test \\
\hline \multirow[t]{4}{*}{ Operation time frame within 6 hours } & NFS & $66.67(4 / 6)$ & $93.75(15 / 16)$ & 0.099 \\
\hline & $\overline{\mathrm{HOL}}$ & $100(4 / 4)$ & $88.89(8 / 9)$ & 0.488 \\
\hline & National (mean) & 61.00 & 61.00 & \\
\hline & Standard \% & $\min .75$ & $\min .75$ & \\
\hline \multirow[t]{4}{*}{ Reoperation } & NFS & $33.33(2 / 6)$ & $31.25(5 / 16)$ & 0.926 \\
\hline & $\mathrm{HOL}$ & $25.00(1 / 4)$ & $11.11(1 / 9)$ & 0.522 \\
\hline & National (mean) & 16.00 & 16.00 & \\
\hline & Standard \% & $\max .10$ & $\max .10$ & \\
\hline \multirow[t]{4}{*}{ Weight control (daily) } & NFS & $33.33(2 / 6)$ & $56.25(9 / 16)^{*}$ & 0.338 \\
\hline & $\overline{\mathrm{HOL}}$ & $33.33(1 / 3)$ & $100(9 / 9)^{*}$ & 0.007 \\
\hline & National (mean) & 33.00 & 61.00 & \\
\hline & Standard \% & $\min .90$ & $\min .90$ & \\
\hline \multirow[t]{4}{*}{ Fluid balance (daily) } & NFS & $66.67(4 / 6)$ & $75.00(12 / 16)$ & 0.696 \\
\hline & $\mathrm{HOL}$ & $100(4 / 4)$ & $88.89(8 / 9)$ & 0.488 \\
\hline & National (mean) & 72.00 & 86.00 & \\
\hline & Standard \% & $\min .90$ & $\min .90$ & \\
\hline \multirow[t]{4}{*}{ Postoperative monitoring (daily) } & NFS & $66.67(4 / 6)$ & $93.75(15 / 16)$ & 0.099 \\
\hline & $\mathrm{HOL}$ & $100(4 / 4)$ & $77.78(7 / 9)$ & 0.305 \\
\hline & National (mean) & 69.00 & 93.00 & \\
\hline & Standard \% & $\min .90$ & $\min .90$ & \\
\hline
\end{tabular}

NFS and HOL compared to the national mean and the national standard: 2008 and 2012.

*Significant differences between hospitals compared in years (two proportions z-test). 
Table 7 Hip fracture indicators

\begin{tabular}{lllll}
\hline Indicator & Location & Pre percent $(\mathbf{n}) \mathbf{2 0 0 8}$ & Post percent (n) 2012 & p-value chi2-test \\
\hline Pain & NFS & $65.89(141 / 214)$ & $85.88(146 / 170)$ & 0.000 \\
\cline { 2 - 5 } & HOL & $81.92(222 / 271)$ & $98.17(161 / 164)$ & 0.000 \\
\cline { 2 - 5 } & National (mean) & $\#$ & 88.00 & min.90 \\
\cline { 2 - 5 } & Standard \% & min.90 & $82.27(181 / 220)$ & 0.000 \\
\hline Rehabilitation & NFS & $95.75(203 / 212)$ & $99.47(187 / 188)$ & 0.006 \\
\cline { 2 - 5 } & HOL & $94.83(257 / 271)$ & 93.00 & \\
\cline { 2 - 5 } & National (mean) & min.90 & min.90 & \\
\cline { 2 - 5 } & Standard \% & &
\end{tabular}

NFS and HOL compared to the national mean and the national standard: 2008 and 2012.

\#Data missing.

quality in treatment is questionable. However, it is likely that an increased focus on early intervention in the ED might have encouraged these results. Therefore, the study indicates that during the period of the establishment of an ED, it was possible to improve the clinical quality in selected services that reflect early diagnosis and treatment. The development of a common set of indicators for monitoring acute treatment at EDs in Denmark is recommended as the indicators available are not specific in terms of acute care and only covers a part of the spectrum needed. We call for a set of validated indicators reflecting the acute changes in patients within 24-48 hours of admission in an ED.

\section{Limitations}

The use of the validated indicators increased the reproducibility; yet, it cannot be excluded that there may be a risk of information bias because of missing or incomplete data records because of the various physicians

Table 8 Mortality

\begin{tabular}{|c|c|c|c|c|}
\hline 30-day Mortality & Locations & Pre percent (n) 2008 & Post percent (n) 2012 & $\mathrm{p}$-value chi2-test \\
\hline \multirow[t]{4}{*}{ Stroke } & NFS & $12.29(36 / 293)$ & $5.66(12 / 212)$ & 0.012 \\
\hline & $\overline{\mathrm{HOL}}$ & $11.81(72 / 652)$ & $8.04(51 / 634)$ & 0.024 \\
\hline & National (mean) & 10.00 & 10.00 & \\
\hline & Standard \% & $\max .15$ & $\max .15$ & \\
\hline \multirow[t]{4}{*}{ COPD } & NFS & $4.35(3 / 69)$ & $8.49(45 / 530)$ & 0.233 \\
\hline & $\mathrm{HOL}$ & $6.61(8 / 121)$ & $10.76(47 / 437)$ & 0.176 \\
\hline & National (mean) & 9.00 & 10.00 & \\
\hline & Standard \% & None & None & \\
\hline \multirow[t]{4}{*}{ Heart failure (1 year mortality) } & NFS & $44.71(60 / 136)^{*}$ & $15.1(31 / 206)$ & 0.000 \\
\hline & $\mathrm{HOL}$ & $33.03(36 / 109)^{*}$ & $\#$ & \\
\hline & National (mean) & $\#$ & 13.00 & \\
\hline & Standard \% & $\max .20$ & $\max .20$ & \\
\hline \multirow[t]{4}{*}{ Bleeding ulcer } & NFS & $3.45(1 / 29)^{*}$ & $9.62(10 / 104)$ & 0.286 \\
\hline & $\mathrm{HOL}$ & $20.00(2 / 10)^{*}$ & $10.94(7 / 64)$ & 0.415 \\
\hline & National (mean) & 9.00 & 9.00 & \\
\hline & Standard \% & $\max .10$ & $\max .10$ & \\
\hline \multirow[t]{4}{*}{ Perforated ulcer } & NFS & $33.33(2 / 6)$ & $31.25(5 / 16)$ & 0.926 \\
\hline & $\overline{\mathrm{HOL}}$ & $25.00(1 / 4)$ & $37.50(3 / 8)$ & 0.665 \\
\hline & National (mean) & 23.00 & 22.00 & \\
\hline & Standard \% & $\max .20$ & $\max .20$ & \\
\hline \multirow[t]{3}{*}{ Hip fracture } & NFS & $11.68(25 / 214)$ & $8.47(21 / 248)$ & 0.251 \\
\hline & $\mathrm{HOL}$ & $11.81(32 / 271)$ & $9.43(20 / 212)$ & 0.406 \\
\hline & Standard \% & $\max 10$ & $\max 10$ & \\
\hline
\end{tabular}

NFS and HOL compared to the national mean and the national standard: 2008 and 2012. *Significant differences between hospitals compared in years (two proportions z-test). \#Data missing. 
reporting data. In general, the data completeness in the databases is high both at the departmental and the national level, only with some insignificant differences [10].

The patient records are comprehensive at the national, regional and departmental levels, but they vary according to the different disease groups. Some issues concerning internal validity are acknowledged by the authors, as the patients' records were reported by different specialist physicians.

We noted a considerable difference in morbidity and mortality among the disease groups, which is why we chose indicators within the three primary specialties of the hospital: medicine, orthopaedic surgery and general surgery.

$\mathrm{HOL}$ is a comparable hospital with the establishment of an ED in April 2009 and with approximately the same activity.

\section{Abbreviations}

ED: Emergency Department; NIP: The National Indicator project; RKKP: Regions clinical quality development; NFS: Nykøbing Falster Hospital; HOL: Holbæk Hospital.

\section{Competing interests}

The authors declare that they have no competing interests.

\section{Authors' contributions}

MSM participated in the conception and design of the present study manage data and interpretation and also drafted and critically revised the manuscript. NM contributed to and critically revised the manuscript. HJ participated in the conception and design of the present study and contributed to and critically revised the manuscript. All authors read and approved the final version of the manuscript.

\section{Acknowledgements}

The authors would like to acknowledge the Emergency Department and the employers for supporting this research project. The authors also thank Professor Terkel Christiansen, for quidance and help during the planning stage, data collection and writing period. Funding was provided by the Research Unit Region Zealand South, Department of Quality and Development in Region Zealand, Edith and Henrik Henriksen's Memorial Fund, The Local Research Fund Region Zealand South and Region Zealand's Health Research Foundation.

\section{Author details}

${ }^{1}$ Faculty of Health Science, University of Southern Denmark, 5230 Odense M, Denmark. ${ }^{2}$ Emergency Department, Hospital of Nykøbing Falster, 4800 Nykøbing Falster, Denmark. ${ }^{3}$ Department of Cardiology, Bispebjerg Hospital, 2400 Copenhagen, NV, Denmark

Received: 2 May 2014 Accepted: 8 October 2014

Published online: 05 November 2014

\section{References}

1. The Danish Health and Medicines Authority: Styrket Akutberedskab planlægningsgrundlag for det regionale sundhedsvæsen; 2007. http:// sundhedsstyrelsen.dk/publ/Publ2007/PLAN/Akutberedskab/ StyrketAkutberedskab.pdf.

2. Holliman CJ, Mulligan TM, Suter RE, Cameron P, Wallis L, Anderson PD, Clem $K$ : The efficacy and value of emergency medicine: a supportive literature review. Int J Emerg Med 2011, 4:44.

3. Joint Commission Resources: Designing for improved patient flow, part 2: structuring space helps keep patients moving, special series: patient flow. Environ Care 2004, 5:8-10.

4. Muntlin Athlin A, von Thiele Schwarz U, Farrohknia N: Effects of multidisciplinary teamwork on lead times and patient flow in the emergency department: a longitudinal interventional cohort study. Scand I Trauma Resusc Emerg Med 2013, 21:76.
5. FitzGerald G, Jelinek GA, Scott D, Gerdtz MF: Emergency department triage revisited. Emerg Med J 2010, 27:86-92.

6. Farrohknia N, Castrén M, Ehrenberg A, Lind L, Oredsson S, Jonsson H, Asplund K, Göransson KE: Emergency department triage scales and their components: a systematic review of the scientific evidence. Scand J Trauma Resusc Emerg Med 2011, 19:42.

7. Wiler JL, Gentle C, Halfpenny JM, Heins A, Mehrotra A, Mikhail MG, Fite D: Optimizing emergency department front-end operations. Ann Emerg Med 2010, 55:160.e1.

8. Kantonen J, Kaartinen J, Mattila J, Menezes R, Malmila M, Castren M, Kauppila T: Impact of the ABCDE triage on the number of patient visits to the emergency department. BMC Emerg Med 2010, 10:12.

9. Oredsson S, Jonsson H, Rognes J, Lind L, Göransson KE, Ehrenberg A, Asplund K, Castrén M, Farrohknia N: A systematic review of triage-related interventions to improve patient flow in emergency departments. Scand J Trauma Resusc Emerg Med 2011, 19:43.

10. Regional clinical quality development programme. In http://www.rkkp.dk/ om+rkkp/de+kliniske+kvalitetsdatabaser.

11. Barfod C, Lauritzen MM, Danker JK, Soletormos G, Berlac PA, Lippert F, Lundstrom $\mathrm{LH}$, Antonsen K, Lange KH: The formation and design of "The Acute Admission Database"- a database including a prospective, observational cohort of 6279 patients triaged in the Emergency Department in a larger Danish hospital. Scand I Trauma Resusc Emerg Med 2012, 20:29.

12. Lassen AT: Syddansk akutkohorte. In http://www.ouh.dk/wm435947.

13. National indicator project, COPD. In http://www.kcks-vest.dk/kliniske +kvalitetsdatabaser/kol? Accessed 26. April 2013.

14. National indicator project, Stroke. In http://www.kcks-vest.dk/kliniske +kvalitetsdatabaser/apopleksi? Accessed 26. April 2013.

15. National indicator project, Hip fracture. In http://www.kcks-vest.dk/kliniske +kvalitetsdatabaser/hoftenære+lårbensbrud? Accessed 26. April 2013.

16. National indicator project, Heart failure. In http://www.kcks-vest.dk/kliniske +kvalitetsdatabaser/hjertesvigt? Accessed 26. April 2013.

17. National indicator project, Acute surgery. In 2012. http://www.kcks-vest. dk/kliniske+kvalitetsdatabaser/akut+kirurgidatabasen? Accessed 26. April 2013.

18. Considine J, Kropman M, Kelly E, Winter C: Effect of emergency department fast track on emergency department length of stay: a case-control study. Emerg Med J 2008, 25:815-819.

19. Skriver C, Mauson M, Lauritzen P, Forberg $J \mathrm{~L}$, Gaardboe-poulsen $\mathrm{OB}$ Mogensen CB: Triage medfører hurtigere behandling af de mest syge. Ugeskr Laeger 2011, 173:2490-2493.

20. St Noble VJ, Davies G, Bell D: Improving continuity of care in an acute medical unit: initial outcomes. QJM 2008, 101:529-533.

21. Greenberg RA, Dudley NC, Rittichier KK: A reduction in hospitalization, length of stay, and hospital charges for group with the institution of a pediatric observation unit. Am J Emerg Med 2006, 24:818-821.

22. Pena ME, Fox JM, Southall AC, Dunne RB, Szpunar S, Kler S, Takla RB: Effect on efficiency and cost-effectiveness when an observation unit is managed as a closed unit vs an open unit. Am J Emerg Med 2013, 31:1042-1046.

23. Schrager J, Wheatley M, Georgiopoulou V, Osborne A, Kalogeropoulos A, Hung O, Butler J, Ross M: Favorable bed utilization and readmission rates for emergency department observation unit heart failure patients. Acad Emerg Med 2013, 20:554-561.

24. Allen D, Rixson L: "care pathway technologies" on service integration in stroke care been measured and what is the strength of the evidence to support their effectiveness in this respect? Int J Evid Based Healthc 2008, 6:78-110.

25. Mattsson MS, Jørsboe H: Danske studier af akutte patientforløb efter opstart af fælles akutmodtagelser. Ugeskr Laeger 2014, 176:1396-1398.

26. Sørup CM, Jacobsen P, Forberg JL: Evaluation of emergency department performance - a systematic review on recommended performance and quality-in-care measures. Scand J Trauma Resusc Emerg Med 2013, 21:62.

27. Crema $M$, Verbano $C$ : Guidelines for overcoming hospital managerial challenges: a systematic literature review. Ther Clin Risk Manag 2013, 9:427-441.

\section{doi:10.1186/s13049-014-0060-4}

Cite this article as: Mattsson et al:: Improvement of clinical quality indicators through reorganization of the acute care by establishing an emergency department-a register study based on data from national indicators. Scandinavian Journal of Trauma, Resuscitation and Emergency Medicine 2014 22:60 